\title{
Tratamiento de las recesiones gingivales mediante injertos de tejido conectivo (Técnica del injerto de tejido conectivo subepitelial). Resultados tras cinco años de evolución.
}

\author{
Blanco Carrión J**. \\ Villaverde Ramírez G*. \\ Ramos Barbosa I**. \\ Bascones Ilundain $\mathrm{J} * * *$. \\ Bascones Martínez $\overline{\mathbf{A}} * * * *$.
}

\author{
Villaverde Ramírez G; Blanco Carrión J; Ramos Barbosa I; Bascones \\ Ilundain J; Bascones Martínez A; Tratamiento de las recesiones gingivales \\ mediante injertos de tejido conectivo (Técnica del injerto de tejido \\ conectivo subepitelial). Resultados tras cinco años de evolución. 2000; 12
}

\begin{abstract}
RESUMEN
Las recesiones gingivales son un hallazgo clínico muy frecuente que a menudo ocasionan problemas estéticos para nuestros pacientes o no les permiten mantener un buen control de placa en estas zonas, lo cual puede derivar en sensibilidades o incluso en caries.

Para su tratamiento se han diseñado diversas técnicas de cirugía mucogingival, siendo el injerto libre de tejido conectivo una de las técnicas que hoy por hoy ofrece mayor porcentaje de éxitos y mayor predictibilidad. Si bien se han descrito diversas formas de trasplantar el injerto conectivo al lecho receptor, centraremos nuestro trabajo en la técnica descrita por Langer y Langer en 1985 que, pese a sufrir diversas modificaciones propuestas por diferentes autores, sigue constituyendo la base fundamental en la utilización de este tipo de injertos. Presentamos resultados tras cinco años de evolución.
\end{abstract}

\section{PALABRAS CLAVE:}

Recesión, cirugía mucogingival, injertos de tejido blando.

\section{INTRODUCCIÓN}

La estética es hoy por hoy uno de los motivos de consulta más importante y frecuente que llevan a los pacientes a nuestras consultas. La periodoncia no es ajena a esta demanda, pues no en vano Miller introdujo en 1988 el concepto de "cirugía plástica periodontal" para referirse a la cirugía mucogingival, la cual aparece definida en el "glosario de términos" de 1992 como el "conjunto de procedimientos de cirugía plástica destinados a corregir defectos en la morfología, posición y/o cantidad de encía en torno a los dientes".
Los injertos libres de tejido conectivo (ILTC) entrarían dentro de la llamada cirugía mucogingival y aunque se realizan injertos de modo preventivo (ortodoncia, preparaciones de márgenes subgingivales) y/o funcional (sensibilidades térmicas, a los sápidos o al simple contacto), en muchas ocasiones se trata de razones mayoritariamente estéticas.

La indicación más frecuente de los ILTC son las recesiones gingivales. Guinard y Caffese (1977) las definían como "denudaciones parciales de una raíz debidas a la migración apical del margen gingival", esto supone pérdida de encía queratinizada y exposición de la superficie radicular. Se trata de un hallazgo clínico

* Alumno Máster de Periodoncia. Facultad de Odontología, Universidad Complutense de Madrid.

** Profesor asociado de Odontología Integrada de Adultos. Facultad de Odontología, Universidad de Santiago de Compostela.

*** Odontólogo. Alumno de tercer ciclo de la Universidad Complutense de Madrid.

**** Catedrático de Medicina Bucal y Periodoncia. Director del Máster del Periodoncia de la Universidad Complutense de Madrid. 
muy frecuente, incluso en países muy desarrollados y con un buen control de placa (Löe 1992, Serino 1994).

\section{ETIOLOGÍA, CLASIFICACIÓN Y PRONÓSTICO DE LAS RECESIONES GINGIVALES}

De acuerdo a Hall (1977) podemos diferenciar entre factores predisponentes, que serían aquellos condicionantes anatómicos que influirían sobre la posición y estabilidad del margen gingival; y factores desencadenantes o determinantes, que incidirían directamente en los anteriores provocando la recesión gingival (tabla 1).

La clasificación de las recesiones gingivales que actualmente se considera más válida es la de Miller que, en 1985, las clasificaba desde un punto de vista clínico en cuatro clases (tabla 2). Esta clasificación la realizaba atendiendo a la situación del margen más apical de la recesión respecto a la línea mucogingival y a la cantidad de tejido perdido (encía y hueso) en las zonas interproximales adyacentes a la recesión. Al mismo tiempo, pronosticaba el éxito terapéutico de cada clase, considerando un recubrimiento total en las clase I y II, un recubrimiento parcial de la raíz expuesta en las clases III y en la clase IV consideraba que no se podía realizar recubrimiento radicular, pero sí aumentar la banda de encía queratinizada.

Miller (1985) define recubrimiento radicular completo, después de la cicatrización total de la zona, cuando se consigue situar el margen gingival a nivel de la línea amelocementaria, el surco gingival tiene una profundidad de sondaje inferior a los dos milímetros y no hay sangrado al sondaje. Algunos autores proclaman que esta cobertura radicular puede ser alcanzada bien de forma primaria (Miller 1985), o bien de forma secundaria como describía Goldman en 1964 como "creeping attachment" al referirse a la migración que sufría el margen gingival en sentido coronal en los meses posteriores a la cicatrización. Migración que se puede producir incluso hasta los nueve meses posteriores a la cirugía (Harris 1997).

\section{INDICACIONES}

A lo largo de las últimas décadas se ha discutido sobre la necesidad o no de una mínima banda de encía insertada en torno a los dientes para mantener su salud periodontal y sobre cuantos milímetros serían necesarios. Así, diversos autores como Corn y cols. en 1962, Lang y Löe en 1972 o Maynard y Wilson en 1979 realizaban distintos apuntes basándose en sus observaciones clínicas.

\begin{tabular}{|l|l|}
\hline Factores predisponentes: & Factores desencadenantes \\
\hline - Banda de encía adheri- & - Traumatismo por cepilla- \\
da estrecha. & do \\
- Frenillos de inserción & - Gingivitis y enfermedad \\
aberrante. & periodontal \\
- Malposiciones dentarias & - Tratamiento ortodóncico \\
- Disarmonías dentoes- & - latrogenia. \\
queléticas. & \\
- Fenestraciones y dehis- \\
cencias alveolares
\end{tabular}

Tabla 1. Factores asociados con la etiología de las recesiones gingivales.

Sin embargo, Dorfman y cols. en 1982 afirmaron que era posible mantener los niveles de inserción de los injertos gingivales libres incluso en ausencia de encía adherida siempre que se mantuviese un adecuado control de placa.

Por otro lado, en 1983, Wenströn y Lindhe realizaban un estudio histológico experimental en perros en donde estudiaban la relación de la cantidad de encía adherida con el grado de inflamación gingival. Estos autores no encontraban diferencias en el volumen del infiltrado inflamatorio entre zonas con bandas anchas o estrechas de encía adherida, simplemente eran más visibles clínicamente debido a un menor grosor de los tejidos gingivales en las zonas con banda estrecha de encía adherida.

Posteriores estudios clínicos longitudinales como los de Kennedy y cols. (1985), Schoo y Van der Velden y cols. (1985), Salkin y cols. (1987), Wennströn y cols. (1987), Freedman y cols. (1992), confirmaban que no es necesario una cantidad mínima de encía adherida para conservar la salud periodontal, siendo en la actualidad más correcto indicarlo como encía adherida adecuada o inadecuada.

En la primera Reunión Europea de Periodoncia (1993) se acordaron las siguientes indicaciones de cirugía mucogingival:

- Motivaciones estéticas

- Aquellas situaciones en las cuales al paciente le resulte difícil mantener un adecuado control de placa en la zona de la recesión y que se pueda mejorar modificando el contorno del margen gingival.

- Previo a tratamiento ortodóncico, en dientes con una encía vestibular fina, cuando se prevé que como consecuencia del movimiento del diente se pueda provocar una dehiscencia ósea. 


\begin{tabular}{|l|l|}
\hline Clase I & $\begin{array}{l}\text { Recesión gingival que no llega a la línea mucogingival sin pérdida interproximal de } \\
\text { tejidos duros o blandos. }\end{array}$ \\
\hline Clase 2 & $\begin{array}{l}\text { Recesión gingival que llega o sobrepasa la línea mucogingival sin pérdida de tejidos } \\
\text { duros o blandos interproximales. }\end{array}$ \\
\hline Clase 3 & $\begin{array}{l}\text { Recesión gingival que se extiende o sobrepasa la línea mucogingival con pérdida de } \\
\text { soporte interproximal apical a la línea amelocementaria pero coronal a la extensión } \\
\text { más apical de la recesión o con malposición dentaria. }\end{array}$ \\
\hline Clase IV & $\begin{array}{l}\text { Recesión gingival que se extiende o sobrepasa la línea mucogingival con pérdida de } \\
\text { soporte interproximal que se extiende hasta el nivel más epical de la recesión. }\end{array}$ \\
\hline
\end{tabular}

Tabla 2. Clasificación de Miller de las recesiones gingivales.

\section{CASOS CLÍNICOS}

\section{Caso $\mathbf{A}$}

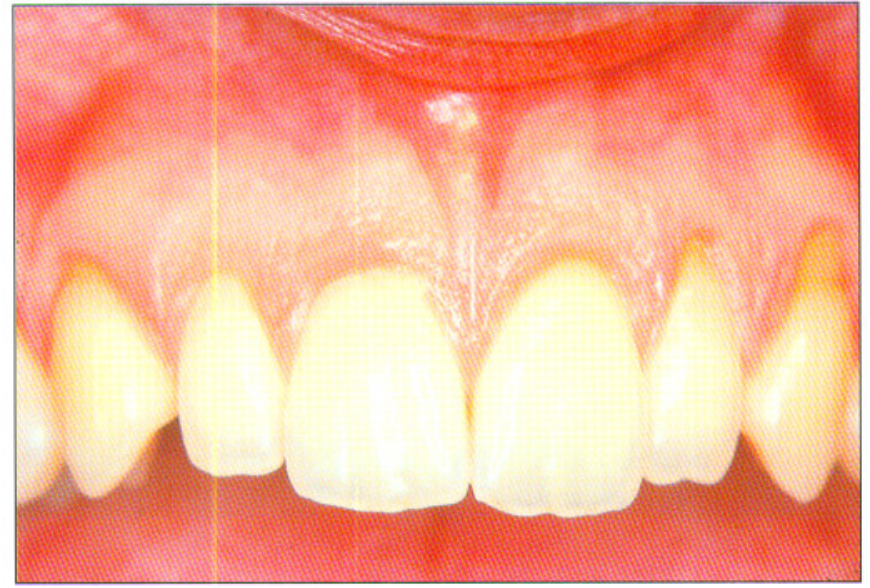

Foto 1 A: Imagen clínica inicial.

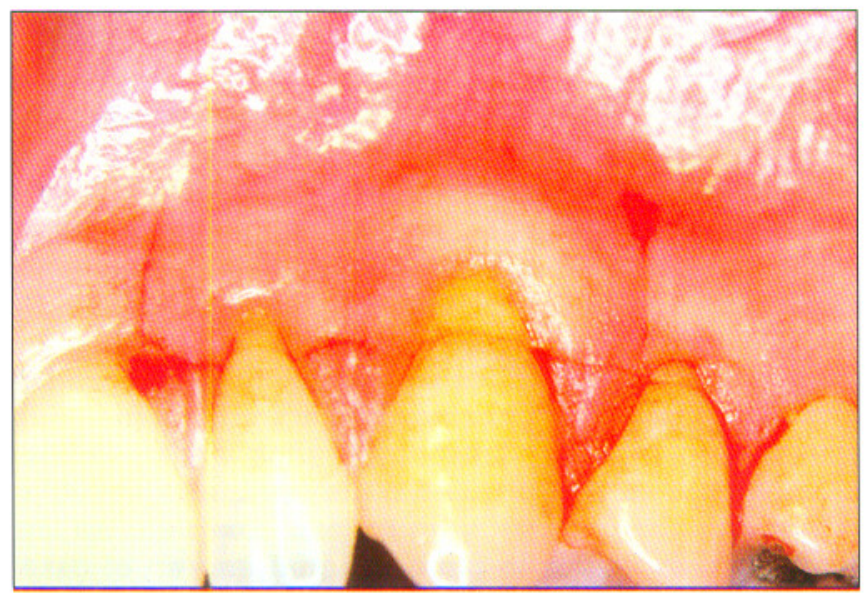

Foto 2 A: Diseño quirúrgico: Incisión horizontal a la altura de las líneas amelocementarias y liberadoras.

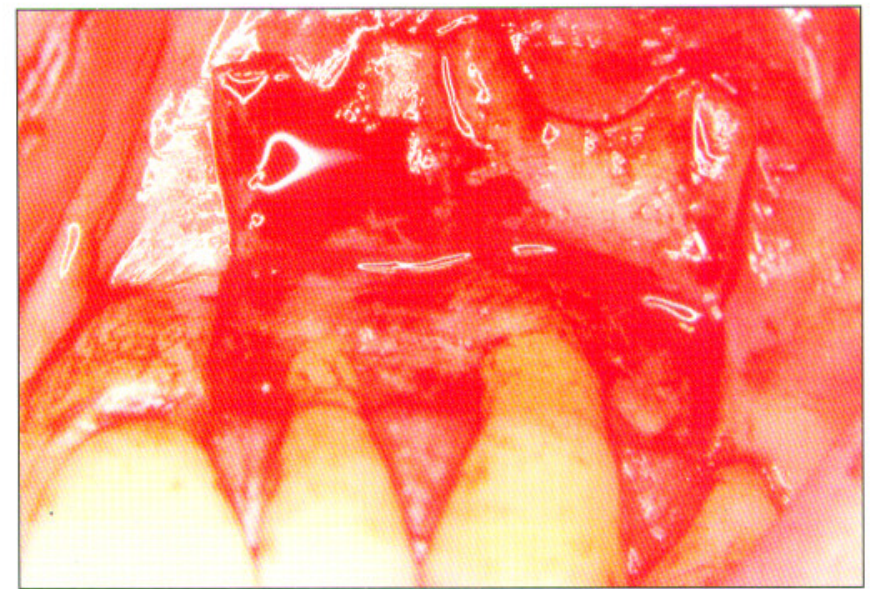

Foto 3 A: Despegamiento a espesor parcial del colgajo y raspado $y$ alisado radicular.

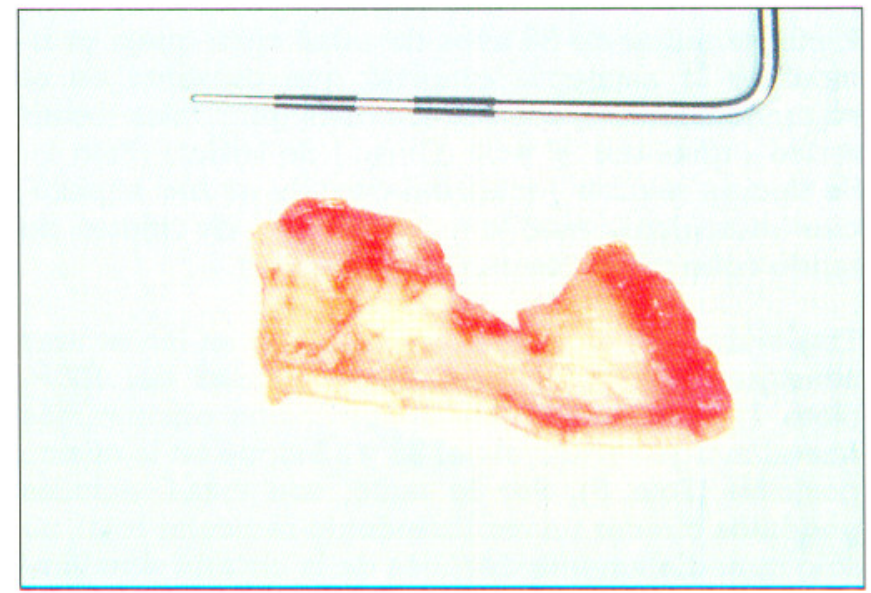

Foto 4 A: Tejido conectivo con margen epitelial extraído de zona palatina. 


\section{AVANCES}

Volumen 12 - $\mathrm{N}^{\circ} 1$ - Mayo 2000

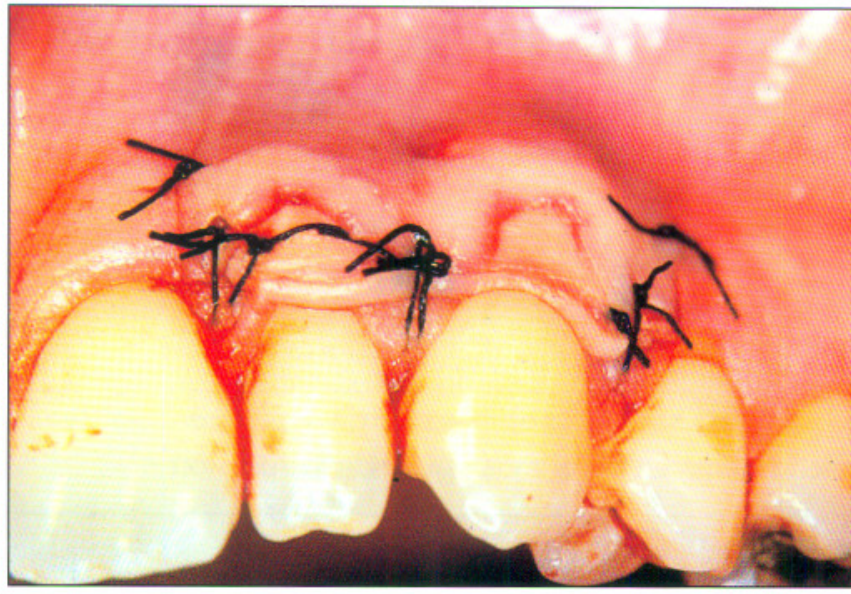

Fotos $5 \mathrm{~A}$ : Sutura del injerto.

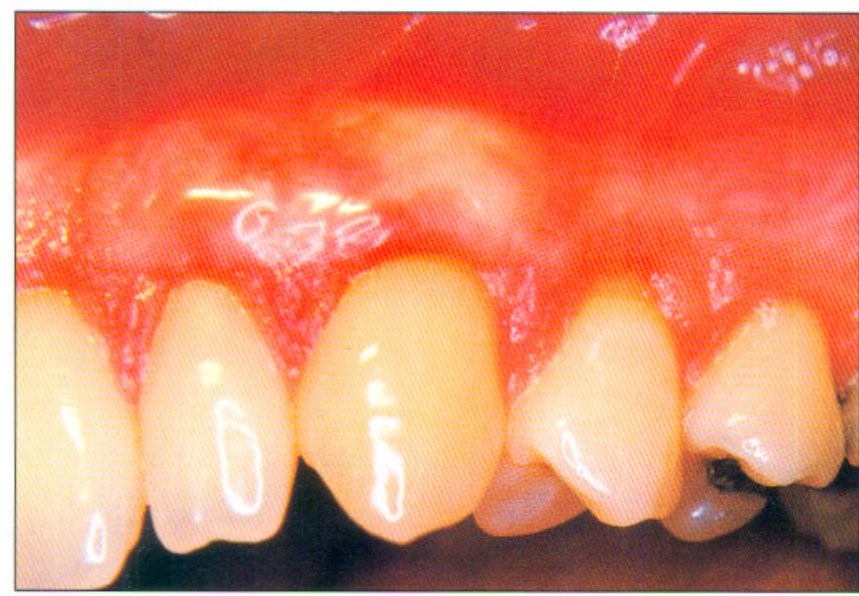

Foto 7 A: Tras dos meses de evolución.

Paciente mujer de 33 años de edad cuya queja principal es la asimetría gingival que presenta en el segundo sextante, con retracciones gingivales localizadas a nivel del 22 y 23 (Clase I de Miller) (Foto 1). Se decide realizar recubrimiento de ambas superficies radiculares mediante la técnica de injerto de tejido conectivo subepitelial (Fotos 2-6).

Tras siete días de cicatrización se retiran las suturas consiguiendo un recubrimiento radicular del $100 \%$ (Foto 7). Tras cinco años de evolución observamos que el margen gingival del 22 y 23 sigue en la misma posición (Foto 8). Por lo tanto, con estas técnicas podemos ofrecer un recubrimiento radicular total, no sólo inmediatamente después de la cirugía sino también a largo plazo.

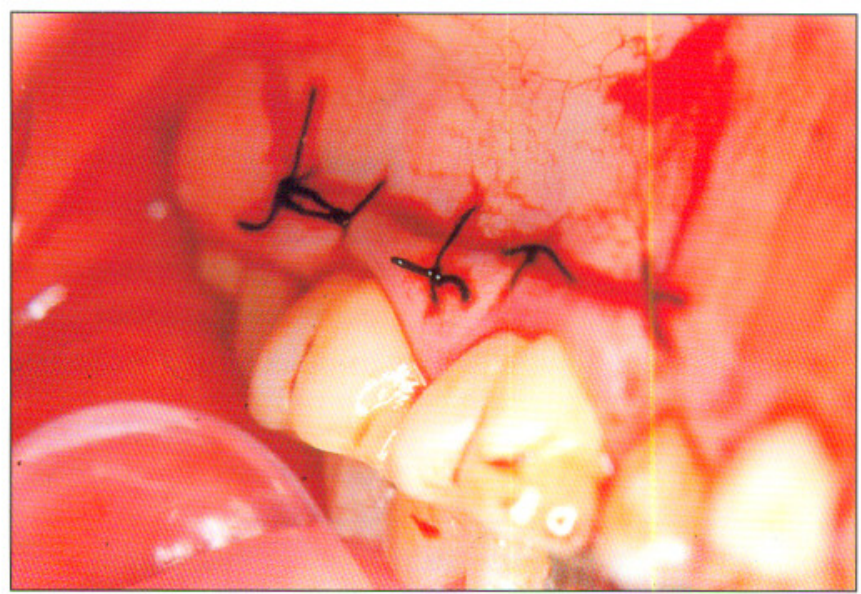

Fotos 6 A: Sutura palatina.

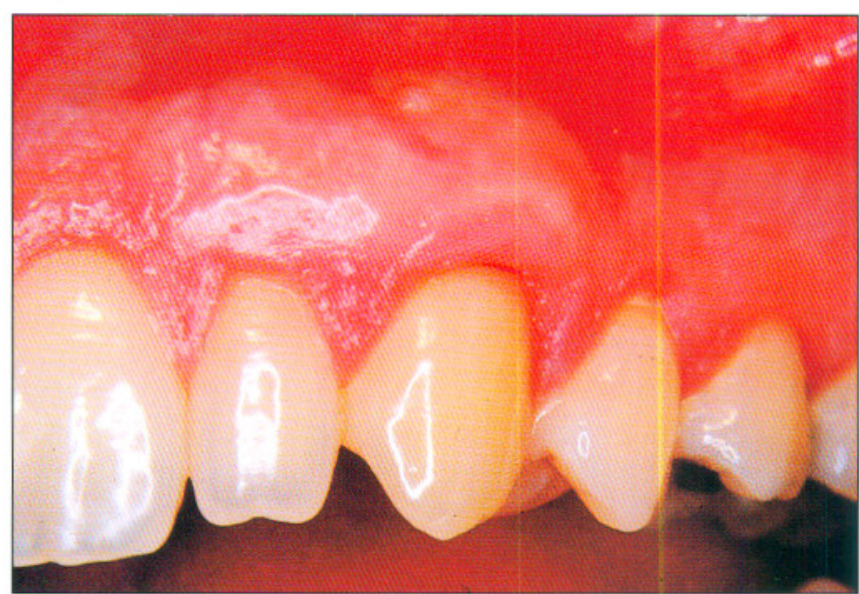

Foto 8 A: Tras cinco años de evolución.

\section{Caso B}

Paciente mujer de 25 años de edad cuyo motivo de consulta son retracciones gingivales a nivel del 13,14 y 15 con sensibilidad radicular (Clase III de Miller) (Foto 1). Se decide realizar el recubrimento de estas raíces mediante la técnica del injerto de tejido conectivo subepitelial (Fotos 2-6).

Se retiran las suturas a los siete días consiguiendo un alto porcentaje de recubrimiento radicular al mes del tratamiento (foto 7). Tras cinco años de evolución observamos un recubrimiento muy próximo al 100\% (Creeping attachment) y un relleno completo de las papilas (Foto 8). Por lo tanto, al igual que en el caso anterior, podemos decir que esta técnica presenta una alta predictibilidad, incluso a largo plazo. 


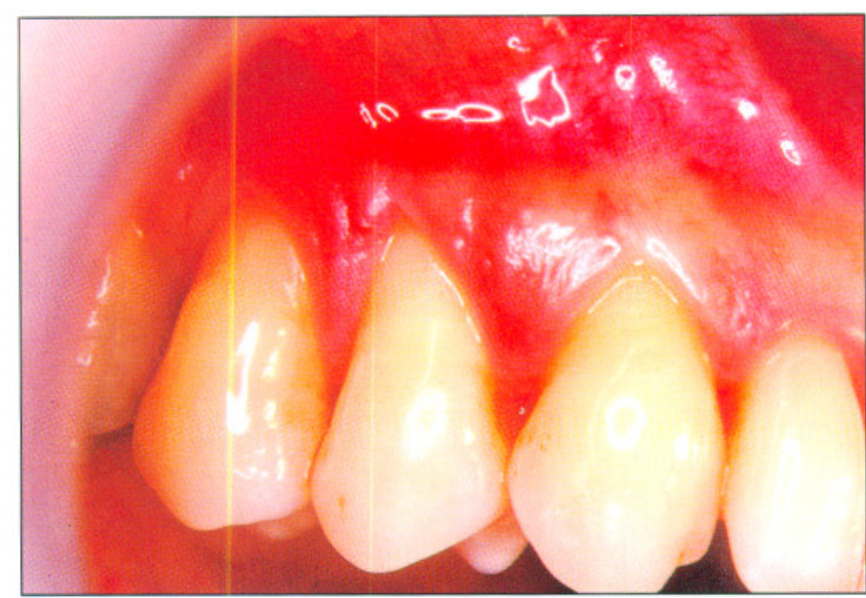

Foto $1 \mathrm{~A}$ : Imagen clínica inicial

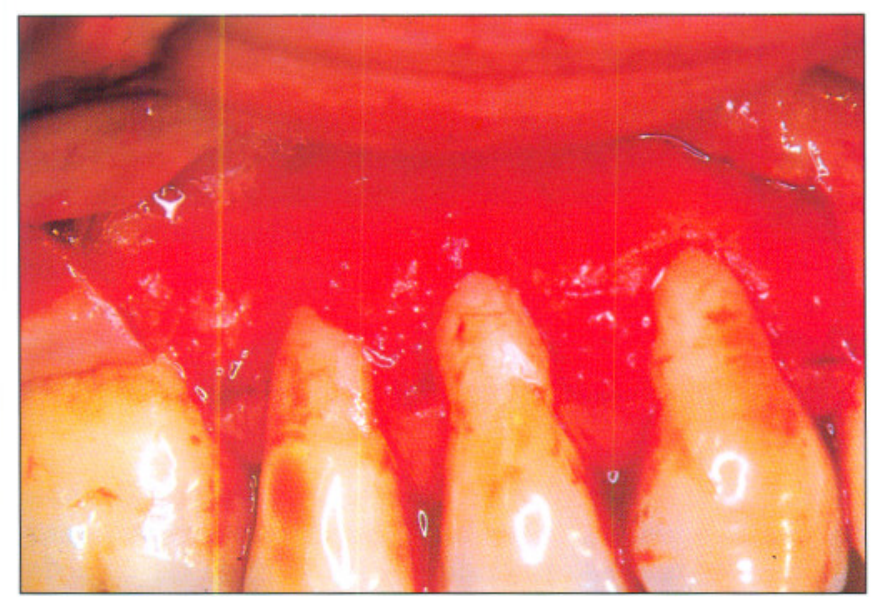

Foto 3 A: Levantamiento del colgajo a espesor parcial e instrumentación de las raíces.

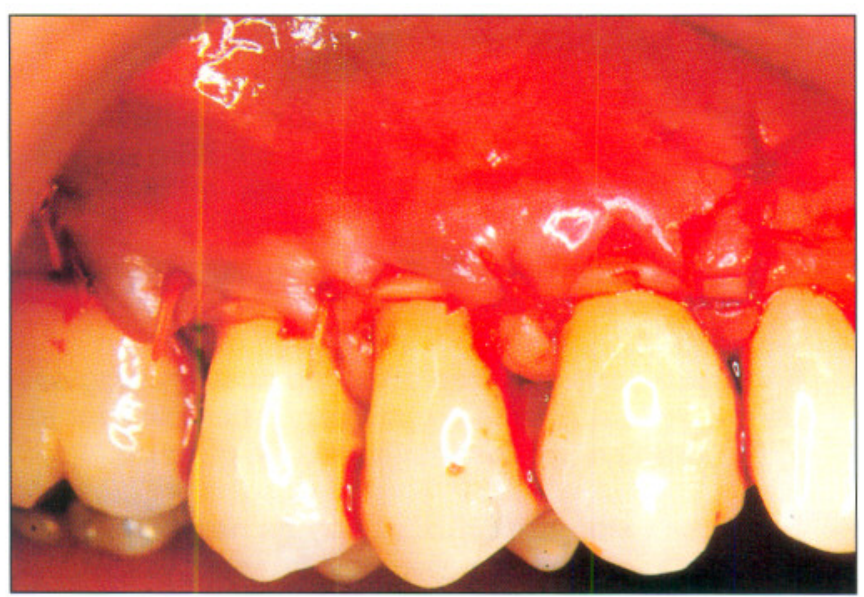

Foto 5 A: Sutura del injerto.

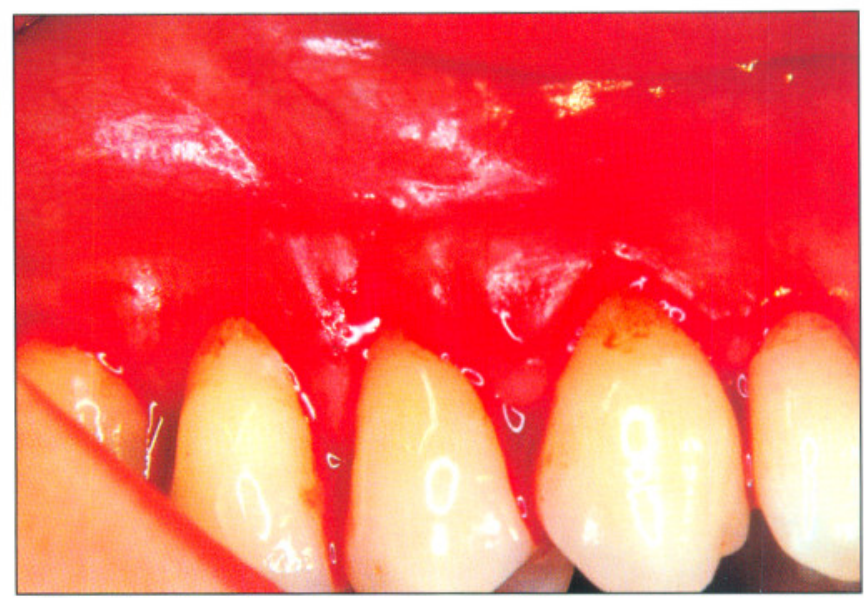

Foto 2 A: Diseño quirúrgico: Incisión horizontal a nivel de las líneas amelocementarias $y$ liberadoras.

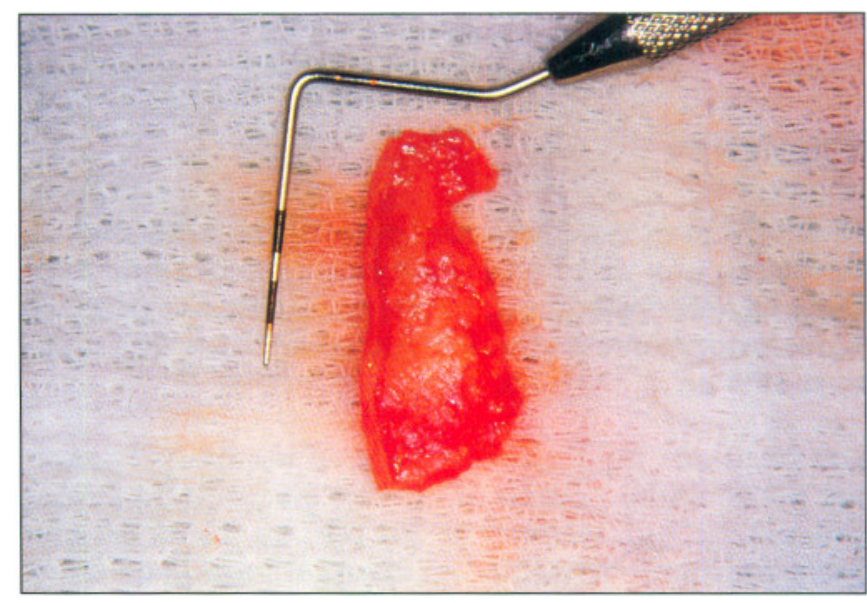

Foto 4 A: Tejido conectivo con margen epitelial extraído de zona palatina

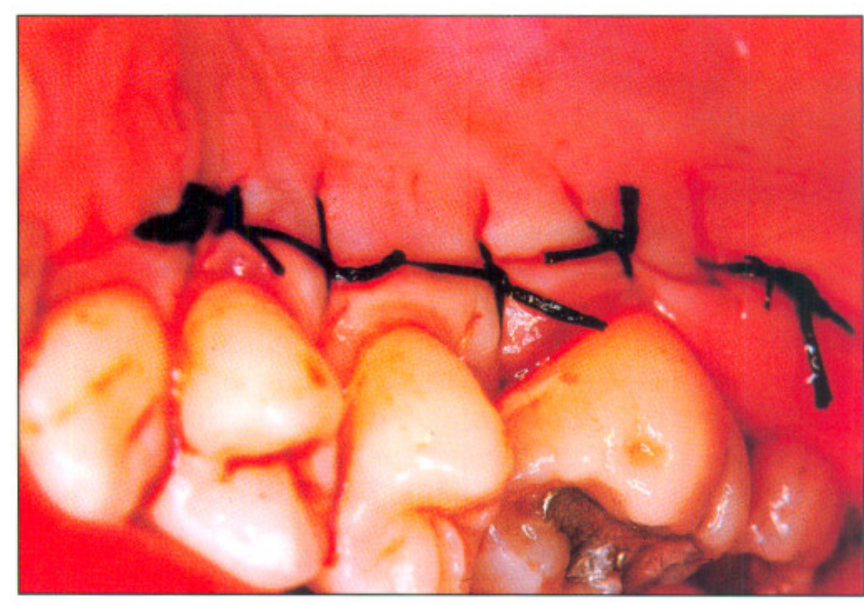

Foto 6 A: Sutura de la zona donante 


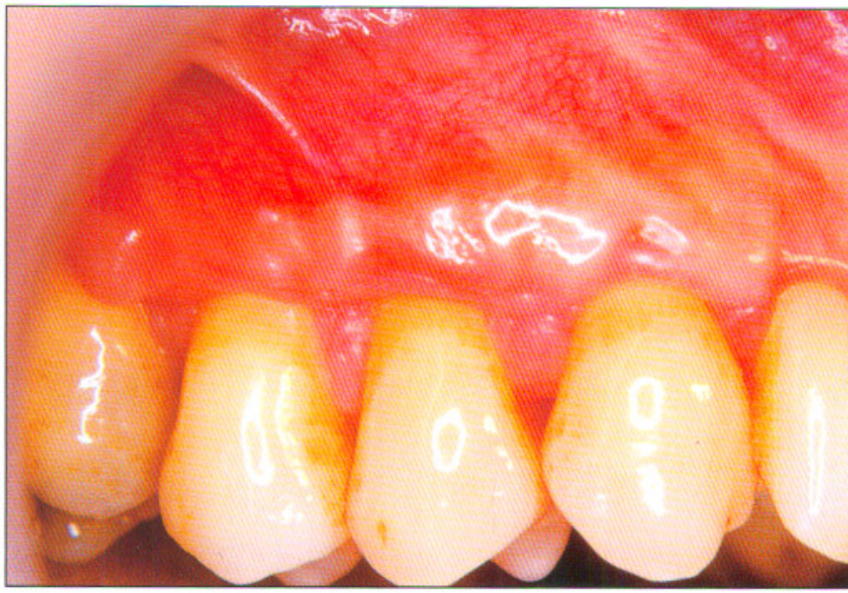

Foto $7 \mathrm{~A}$ : Tras un mes de evolución el recubrimiento no es completo.

\section{Discusión}

El problema de la recesión gingival ha sido tratado mediante una amplia variedad de técnicas quirúrgicas pretendiendo ganar encía queratinizada primero y posteriormente tratando de conseguir recubrimiento radicular.

Los primeros intentos se realizaron mediante "colgajos pediculados" como el colgajo pediculado lateral presentado por Grupe y Warren en 1956, al que posteriormente se sumarían diversas modificaciones. Estos colgajos pueden dividirse, según la dirección de desplazamiento, en colgajos rotados o colgajos desplazados coronalmente. Entre los inconvenientes de este tipo de técnica destaca la necesidad de una suficiente banda de encía queratinizada en la región adyacente a la recesión y el no poder tratar recesiones múltiples. De igual modo, la estética y su relativa facilidad técnica destacarían entre sus ventajas.

Si no disponemos de un adecuado tejido donante en la zona adyacente, debemos recurrir a los injertos libres de encía. Los primeros en desarrollarse fueron los llamados "injertos libres de encía" (epitelioconectivo). En 1963, Björn introdujo la técnica del injerto gingival libre autógeno, aunque serían Sullivan y Atkins los que describirían detalladamente el procedimiento. Posteriormente se sumarían diversas modificaciones (Miller 1982). Entre los inconvenientes de este tipo de injertos destacan sus problemas estéticos (rugets palatinos) y el delicado postoperatorio del paladar. Salvo Miller (1985), el resto de los autores han descrito peores resultados que con otras técnicas.

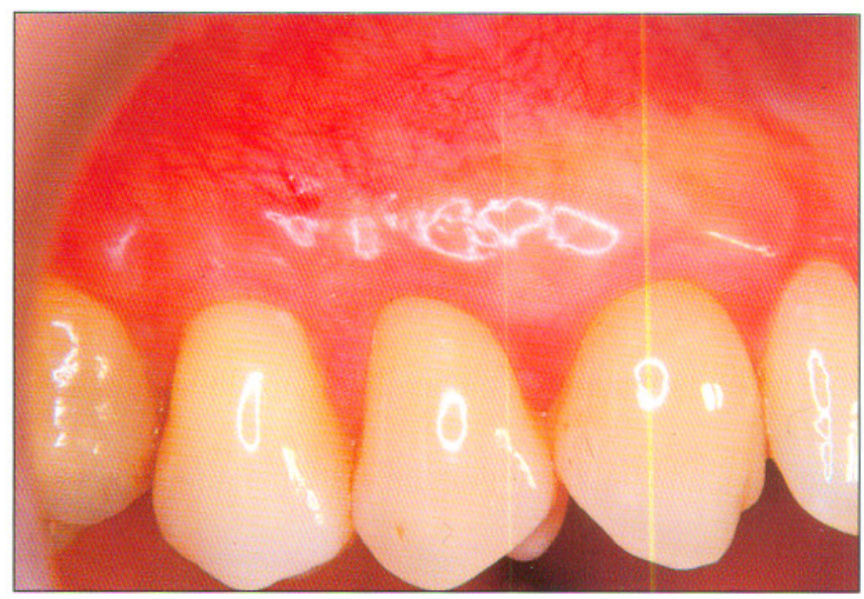

Foto 8 A: Tras cinco años de evolución el recubrimiento es completo (Creeping attachment). Obsérvese el relleno de las papilas

Posteriormente, y con un desarrollo más o menos paralelo aparecieron los "injertos de tejido conectivo subepitelial". Este tipo de injertos se fundamentan en los estudios de Karring y cols. en 1972 y en los de Stambaugh y Gordon en 1974, que demostraban en modelos animales que las características del tejido epitelial vienen determinadas genéticamente por el tejido conectivo subyacente.

Esta técnica, descrita por Edel en 1974 y popularizada por Langer y Langer en 1985, constituye, a pesar de sus diversas modificaciones, la técnica de cirugía mucogingival de elección a la hora de enfrentarnos a una recesión gingival, sobre todo si buscamos cobertura radicular. Esto se debe a:

- Estética: evitamos el aspecto queloide de los injertos palatinos epitelizados.

- Doble aporte sanguíneo al colgajo: por un lado el periostio y por otro el colgajo que cubre el injerto, lo cual aumenta la supervivencia del injerto.

- Menores molestias postoperatorias: la herida palatina cicatriza por primera intención.

- Se puede combinar con otras técnicas quirúrgicas de colgajos mucosos o gingivoplastias para mejorar la estética y/o los resultados en general.

- Posee una alta predictibilidad y ha demostrado su eficacia incluso en pacientes fumadores (Harris 1994).

- Sin embargo, se trata de una técnica más compli- 
cada $\mathrm{y}$, en ocasiones, no poseemos suficiente espesor de tejido conectivo en el paladar.

Desde que en 1990, Tinti y cols., aplicaban los principios de la regeneración tisular guiada al tratamiento de las recesiones gingivales, numerosos han sido los intentos por lograr mejores resultados frente a la cirugía mucogingival. Aunque el objetivo de esta técnica sea el conseguir "nueva inserción", no se han conseguido coberturas radiculares similares a los tratamientos con injertos libres de encía. Sin embargo, se debería valorar el pronóstico del diente a largo plazo frente a ambas técnicas.

\section{SUIMIMARY}

Gingival recession is a very often clinic complaint which frecuently cause esthetic problems to our patients or do not allow them keeping a good plaque control in these areas which can lead to sensibility or even decay.

For their treatment, some techniques of mucogingival surgery have been designed, being the connective tissue free graft, so far, one that offers bigger percentage of success as well as greater predictibility. Although have been described some ways to graft the connective tissue to the recipient bed, we will focus our work on the technique described by Langer and Langer in 1985 which, in spite of suffering several changes proposed by different authors, it is still the fundamental basis in the use of this kind of grafts. We show results after five years post surgery.

\section{KEY WORDS:}

Recession, mucogingival surgery, soft tissue grafts.

\section{CORRESPONDENCIA}

Juan Blanco Carrión

C/ Dr. Teijeiro $33,1^{\circ} \mathrm{D}$

15701 Santiago de Compostela

\section{BIBLIOGRAFÍA}

1. Björn H. Free transplantation of gingiva propia. Sveriges Tandläkarförbunds Tidning 1963; 22: 684.

2. Corn H. periosteal separation-its clinical significance. J Periodontol 1962; 33: 140-52.

3. Dorfman H, Kennedy J, Bird W. Longitudinal evaluation of free autogenous gingival grafts. A four year report. J Periodontol 1982; 53: 349-52.

4. Edel A. Clinical evaluation of free connective tissue grafts used to increase the width of keratinised gingiva. J Clin Periodontol 1974; 1: 185-196.

5. Freedman $\mathrm{AL}$, Salkin LM, Stein MD, Green K. A 10-year longitudinal study of untreated mucogingival defects. J Periodontol 1992; 63: 71-2.

6. Glosary of Terms in Periodontology. J Periodontol 1992; 63 (Suple).

7. Goldman H, Schluger S, Fox L, Cohen DW. Periodontal therapy. 3rd de. St. Louis: C.V. Mosby Co. $1964 ; 560$.

8. Grupe HE, Warren R. Repair of gingival defects by a sliding flap operation. J Periodontol 1956; 27: $92-99$.

9. Guinard EA, Caffesse RG. Treatment of localized gingival recesions Y. Lateral sliding flap. J Periodontol 1977; 48: 351-6.

10. Hall WB. Present status of tissue graffting. J Periodontol 1977; 48: 587-92.

11. Harris, Randall J. Creeping attachment associated with the connective tissue with partial-thickness double pedicle graft. J Periodontol 1997; 68: 890-9.

12. Karring T, Lang NP, Löe H. Role connective tissue in determining epithelial specifity. J Dent Research 1972; 51: 1303-4.

13. Kennedy JE, Bird WC, Palcanis KG, Dorfman HS. A longitudinal evaluation of varying Widths of attached gingiva. J Clin Periodontol 1985; 12: 667-75.

14. Lang NP, Löe H. The relationship between the width of keratinized gingiva and gingival healt. J Periodontol 1972; 43: 623-627.

15. Langer B \& Langer L. Subepitelial connective tissue graft technique for root coverage. J Periodontol 1985; 56: 715-20. 
16. Löe H, Anerud A, Boysen H. The natural history of periodontal disease in man: prevalence, severety, extent of gingival recesion. J periodontol 1992; 63: 489-95.

17. Maynard IG, Wilson RD. Physiologic dimensions of the periodont significant to the restorative dentist. J Periodontol 1979; 50: 170-174.

18. Miller PD. A classification of marginal tissue recession. Int J Periodont Rest Dent 1985; 5: 9-13.

19. Miller PD. Root coverage using a free soft tissue autograft following citric acid aplication. III. A successful and predictable procedure in areas of deep-wide recession. Int J Periodont Rest Dent 1985; 5: 15-37.

20. Miller PD. Regenerative and reconstructive periodontal plastic. Dental Clinic of North America 1988; 32: 287-306.

21. Salkin Lm, Freedman AL, Steim MD, Bassiouny MA. A longitudinal study of untreated mucogingival defects. J Periodontol 1987; 164-6.

22. Schoo WH, Van der Velden U. Marginal soft tissue recession with and without attached gingiva. A five year longitudinal study. J Periodontol 1985; 20 (2): 209-11.
23. Serino G, Wennstróm J, Lindhe J, Eneroth Y. The prevalence and distribution of gingival recesion in subjets with a high standar of oral hygiene. J Clin Periodontol 1994; 21: 57-63.

24. Stambaugh RU, Gordon HP. Connective tissue influence on mucosal keratinization. J Dent Res (special issue) 1974; 52: 14t.

25. Sullivan H, Atkins J. Free autogenous gingival grafts. III. Utilization of grafts in the treatment of gingival recession. Periodontics 1962; 6: 152.

26. Tinti C, Vincenzi G. II trattamento delle recessioni gengivali con la tecnica di regenerazione guidata dei tessuti mediante menbrane Gore-tex: variante clinica. Quintessence Int 1990; 6: 465-8.

27. Wennström JL, Lindhe J. Plaque-induced gingival inflammation in the absence of attached gingivaa in dogs. J Clin Periodontol 1983; 10: 266-76.

28. Wennström JL. Lack of association between width of attached gingiva and development of gingival recessions. A 5-year longitudinal study. J Clin Periodontol $1987 ; 14: 181-4$. 